\title{
Mean diurnal variations of noctilucent clouds during 7 years of lidar observations at ALOMAR
}

\author{
J. Fiedler, G. Baumgarten, and G. von Cossart \\ Leibniz-Institut für Atmosphärenphysik an der Universität Rostock, Kühlungsborn, Germany \\ Received: 20 October 2004 - Revised: 9 March 2005 - Accepted: 14 March 2005 - Published: 3 June 2005
}

\begin{abstract}
From 1997 to 2003, noctilucent clouds (NLC) were observed by lidar above the ALOMAR observatory in Northern Norway $\left(69^{\circ} \mathrm{N}\right)$ during a total of 1880 measurement hours. This data set contains NLC signatures for $640 \mathrm{~h}$, covering all local times, even during the highest solar background conditions. After data limitation imposing a threshold value of $4 \times 10^{-10} \mathrm{~m}^{-1} \mathrm{sr}^{-1}$ for the volume backscatter coefficient of the NLC particles, a measure for the cloud brightness, local time dependencies of the NLC occurrence frequency, altitude, and brightness were determined. On average, over the 7 years NLC occurred during the whole day and preferably in the early morning hours, with a maximum occurrence frequency of $\sim 40 \%$ between 4 and 7 LT. Splitting the data into weak and strong clouds yields almost identical amplitudes of diurnal and semidiurnal variations for the occurrence of weak clouds, whereas the strong clouds are dominated by the diurnal variation. NLC occurrence, altitude, as well as brightness, show a remarkable persistence concerning diurnal and semidiurnal variations from 1997 to 2003, suggesting that NLC above ALOMAR are significantly controlled by atmospheric tides. The observed mean anti-phase behavior between cloud altitude and brightness is attributed to a phase shift between the semidiurnal components by $\sim 6 \mathrm{~h}$. Investigation of data for each individual year regarding the prevailing oscillation periods of the NLC parameters showed different phase relationships, leading to a complex variability in the cloud parameters.
\end{abstract}

Keywords. Atmospheric composition and structure (cloud physics and chemistry) - Meteorology and atmospheric dynamics (Middle atmosphere dynamics)

\section{Introduction}

Noctilucent clouds (NLC) are the highest clouds of the Earth's atmosphere and a visible sign of the extreme conditions at the polar mesopause region. They occur during summer at high latitudes in an altitude range between 80 and

Correspondence to: J. Fiedler

(fiedler@iap-kborn.de)
$90 \mathrm{~km}$ and are bound to the existence of water vapor in combination with very low temperatures. The latter can reach values as low as $130 \mathrm{~K}$, which is considerably lower than the radiation equilibrium temperature, leading to the formation of ice particles.

After their discovery in the 1880 s, first detailed studies regarding the appearance and properties of NLC were initiated by ground-based observers using the naked eye (Jesse, 1887). During the 1960s this method was renewed, leading to long data sets of 33 and 40 years for observations from northwest Europe (Gadsden, 1998) and Moscow (Romejko et al., 2003), respectively. These data series include information about the seasonal and interannual variation of NLC occurrence frequency and brightness. Because observation conditions are limited to the time after dawn when the Sun still illuminates the NLC region, this method cannot provide insight into the behavior of the cloud layers during daytime. In the course of technological development other methods for NLC research, have become available, like rocket-borne, satelliteborne, as well as ground-based instruments. While in-situ techniques are capable of measuring various parameters with high temporal and spatial resolution inside the observation volume, e.g. (Goldberg et al., 2001), remote-sensing instruments are able to investigate NLC on a long-term basis. NLC have been studied successfully from space by various satellites (Donahue et al., 1972; Thomas et al., 1991; Hervig et al., 2001; Shettle et al., 2002; Carbary et al., 2003; DeLand et al., 2003), giving evidence that the particles consist of water ice and are found in both hemispheres at middle to high latitudes during summer.

Since the first detection of a noctilucent cloud by active optical remote sensing in 1989 (Hansen et al., 1989), the lidar technique plays an increasing role in NLC research, as it combines long-term observations with high sensitivity, precision, as well as reproducibility for determination of cloud parameters. From lidar observations it is possible to derive the size and shape of NLC particles, as well as the horizontal structure of cloud layers (von Cossart et al., 1999; Baumgarten et al., 2002a,b). Additionally, multi-annual monitoring of NLC at a given location has shown the variability of occurrence frequency and layer parameters within the season and as a function of years (Fiedler et al., 2003, 2004). 
NLC observations on a regular basis by lidar require a location well inside the polar cap of their usual occurrence, the border of which is around $60^{\circ}$ for the Northern Hemisphere (Gadsden, 1998). Measurements at these high latitudes during summer require daylight capability of the lidar systems, which are only featured in a few stations (Müller et al., 1997; Chu et al., 2003; Thayer et al., 2003; Fiedler et al., 2003; Höffner et al., 2003). Even less of them are able to cover the noon period with sufficient signal quality.

Observations at ALOMAR $\left(69^{\circ} \mathrm{N}\right)$ during 1997 showed significant tidal signatures for NLC altitude as well as backscatter ratio with dominating semidiurnal variations (von Zahn et al., 1998). Measurements at the South Pole during the 2 seasons, 1999-2000 and 2000-2001, also indicated strong diurnal and semidiurnal variations of these parameters but with different phase relations (Chu et al., 2003). Here we report on the diurnal variability of NLC occurrence frequency and layer parameters, as seen above ALOMAR between 1997 and 2003.

\section{Instrumentation and data analysis}

The ALOMAR Rayleigh/Mie/Raman (RMR) lidar is an active remote sensing instrument for investigation of the Arctic middle atmosphere during day and night. It is located at the island of Andøya in Northern Norway $\left(69^{\circ} \mathrm{N}, 16^{\circ} \mathrm{E}\right)$ and operated on a routine basis to measure relative density profiles and aerosol properties in the stratosphere and mesosphere. One of the major tasks is the observation of noctilucent clouds which is done from 1 June to $15 \mathrm{Au}-$ gust since 1997. For the measurements reported here we use a frequency-doubled Nd:YAG laser at $532 \mathrm{~nm}$, whose wavelength is actively stabilized by iodine absorption spectroscopy. At the receiving side a $1.8-\mathrm{m}$ diameter telescope (field-of-view $180 \mu \mathrm{rad}$ ), in combination with a double Fabry-Perot interferometer having an effective spectral bandwidth of about $4 \mathrm{pm}$ (FWHM) is used (von Zahn et al., 2000). These methods result in the ability to detect NLC during all local times of the Arctic summer.

The photodetector records photons emitted by the lidar and backscattered from air molecules and NLC particles as a function of altitude $z$ and sunlight scattered by the atmosphere. After subtraction of both solar background and thermionic emission of the detector an altitude profile of the total backscatter signal $S(z)$ is obtained. The ratio of the measured total backscatter signal $S(z)$ and the molecular signal $S_{M}(z)$ yields the backscatter ratio $R(z)$ as a measure for the presence of NLC particles:

$R(z)=\frac{S(z)}{S_{M}(z)}=\frac{\beta_{M}(z)+\beta_{N L C}(z)}{\beta_{M}(z)}$,

where $\beta_{M}(z)$ and $\beta_{N L C}(z)$ are the volume backscatter coefficients for air molecules and NLC particles, respectively. Using air densities from Lübken (1999) to derive $\beta_{M}(z)$ at the lidar location, the volume backscatter coefficient $\beta_{N L C}(z)$ is calculated. For better readability we will use the term brightness as a synonym for the maximum value $\beta_{\max }$ of the altitude profile $\beta_{N L C}(z)$ and will give $\beta$-values always in units of $10^{-10} \mathrm{~m}^{-1} \mathrm{sr}^{-1}$, unless otherwise stated. The NLC altitude is described by its centroid value $z_{c}$.

From the time resolution of $167 \mathrm{~s}$ defined by the data acquisition we calculate 14-min means and check these profiles for a minimum required signal quality $S / \Delta S>2$ at $55 \mathrm{~km}$ altitude, where $\Delta S$ is the corresponding measurement error. The verified data are searched for NLC signatures which results in 2 data sets containing total and NLC measurements, respectively. Following this procedure, from a total of 1880 measurement hours between 1997 and 2003 noctilucent clouds have been observed during 640 hours, which is, to our knowledge, the most extensive lidar acquired NLC archive. More detailed information regarding the data processing can be found in Fiedler et al. (2003).

\section{Observations}

The temporal distribution of the total lidar measurements on different time scales is given in Fig. 1, indicating a good coverage for our NLC investigations. The ratio of time NLC over total measurements results in the occurrence frequency of noctilucent clouds. We have arranged the data for local times (LT), which is universal time (UT) plus 1 hour and it differs from local solar time only by 4 min. Figure 2 shows the hourly mean values of the occurrence frequency for the accumulated data from 1997 to 2003 . On average, over 7 years NLC occur during the whole day and preferably in the early morning hours.

The upper panel of Fig. 2 shows curves for 2 different thresholds of $\beta_{\max }$ which limits the cloud brightness to certain classes. The value of $\beta_{\max }>0$ means all NLC observed during the considered time period, whereas $\beta_{\max }>4$ limits the data set to clouds having a brightness observable during all local times, even under less favorable measurement conditions. This data set is independent of the solar elevation which was addressed in detail in Fiedler et al. (2003) for the years 1997 until 2001 and also holds for the later years. To be unaffected by the NLC detection efficiency variation, only data for $\beta_{\max }>4$ will be used. Note that we ignore $30 \%$ of the NLC observations by this method. We find the maximum occurrence of brighter NLC with approx. $40 \%$ between 4 and 7 LT, followed by a steep decrease to values around $18 \%$ from 9 to $23 \mathrm{LT}$.

The lower panel of Fig. 2 shows the occurrence frequencies of weak $\left(\beta_{\max }=4-7\right)$ and strong $\left(\beta_{\max }>13\right)$ NLC following the brightness definitions in Fiedler et al. (2003). Both weak and strong clouds have the morning maximum but the weak ones have a clear second maximum during the afternoon. Harmonic fits $F(t)$ to the data regarding periods of 24 as well as $12 \mathrm{~h}$ have been done using the following equation:

$F(t)=A_{0}+A_{12} \cos \left[\frac{2 \pi}{12}\left(t-\phi_{12}\right)\right]+A_{24} \cos \left[\frac{2 \pi}{24}\left(t-\phi_{24}\right)\right]$ 

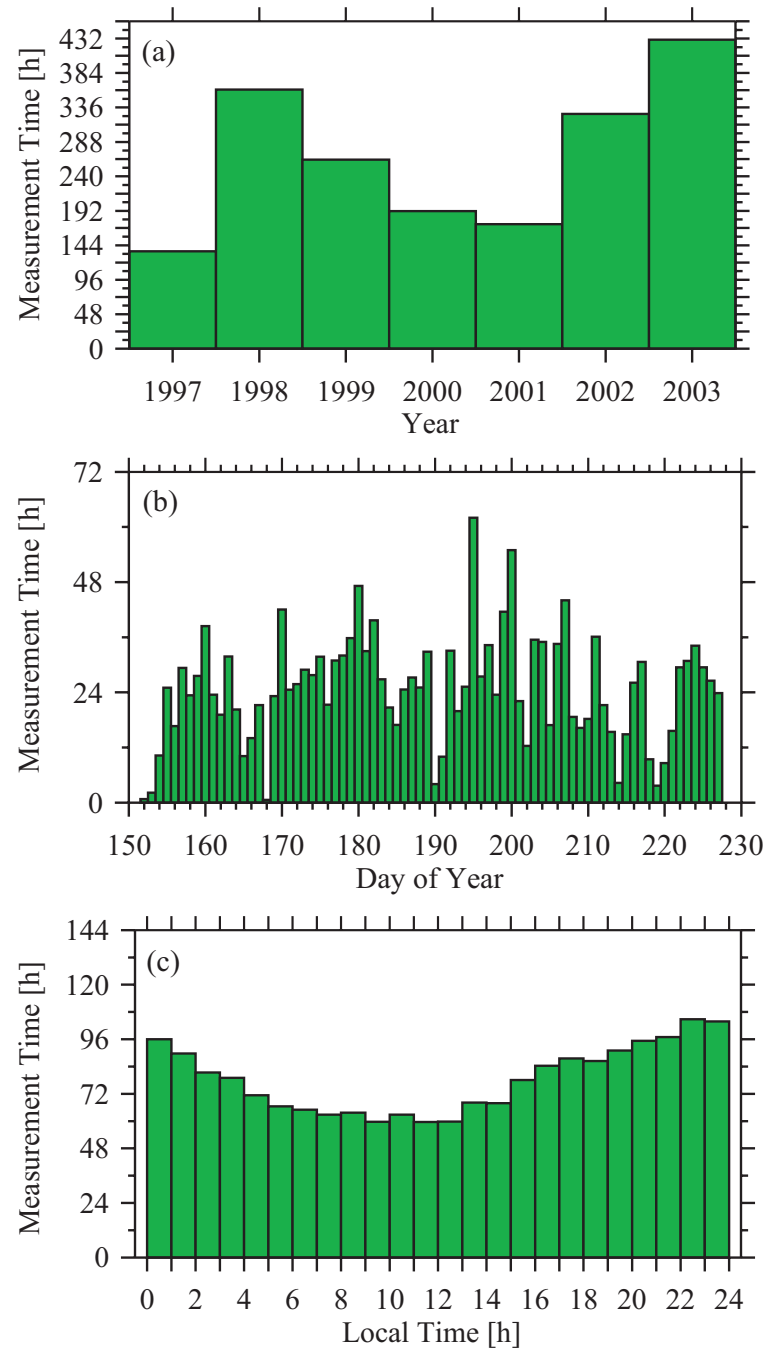

Fig. 1. Time distribution of the ALOMAR RMR lidar total measurements as a function of years (a), season (b), and day (c) between 1 June and 15 August from 1997 to 2003.

where $A$ and $\phi$ are the amplitudes and phases of the allowed wave components, $A_{0}$ is the mean value of the data set, and $t$ is time (LT) in hours. This method yields correlation coefficients of 0.81 and 0.97 for the weak and strong clouds, respectively. While the diurnal and semidiurnal amplitudes of the occurrence frequency of the weak clouds are almost identical $\left(\left|A_{24} / A_{12}\right|=1.03\right)$, the strong clouds show a dominating diurnal variation $\left(\left|A_{24} / A_{12}\right|=2.18\right)$.

For further characterization of the properties of noctilucent clouds we use their brightness and altitude, expressed by the maximum value of the volume backscatter coefficient $\beta_{\text {max }}$ and the centroid altitude $z_{c}$, respectively. Figure 3 shows the diurnal variation of these parameters for the accumulated data set from 1997 to 2003. The vertical bars represent the 95\% significance limits of the hourly mean values, each containing between 8 and 33 measurement hours. Both diurnal and semidiurnal components are substantially responsible for the variations of altitude $\left(\left|A_{24} / A_{12}\right|=0.78\right)$ and brightness
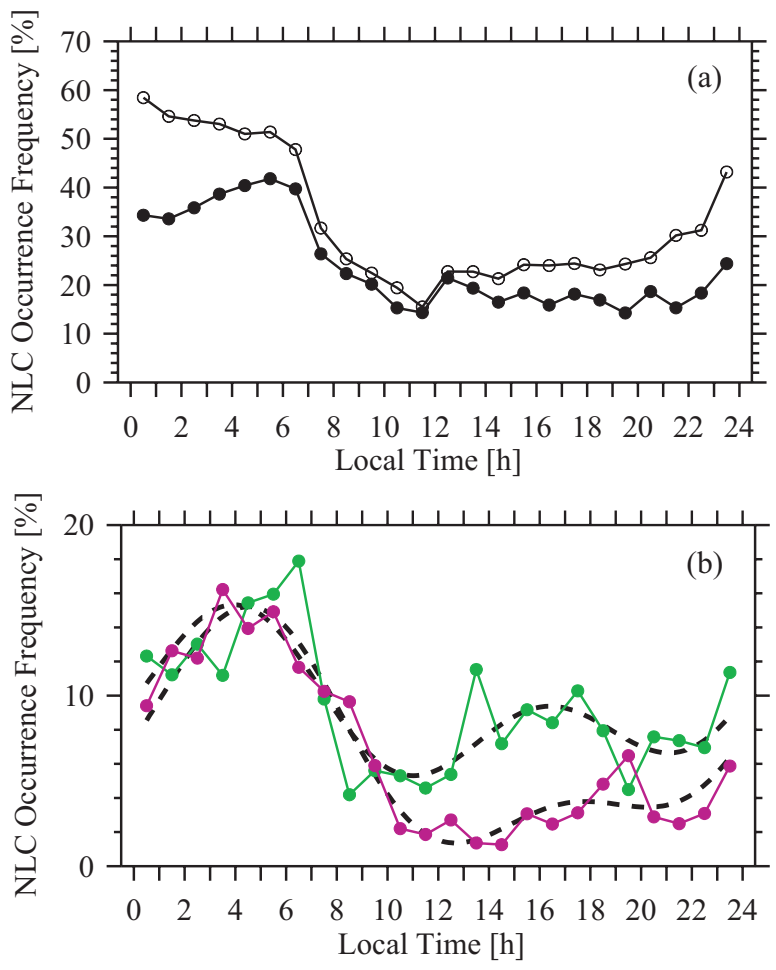

Fig. 2. Diurnal occurrence of NLC above ALOMAR for the integrated data set from 1997 to 2003, sorted by brightness classes. (a) $\beta_{\max }>0$ (black hollow circles) and $\beta_{\max }>4$ (black filled circles). (b) $\beta_{\max }: 4-7$ (green circles) and $\beta_{\max }>13$ (magenta circles). The brightness values are in units of $10^{-10} \mathrm{~m}^{-1} \mathrm{sr}^{-1}$, the dashed curves are harmonic fits to the data.

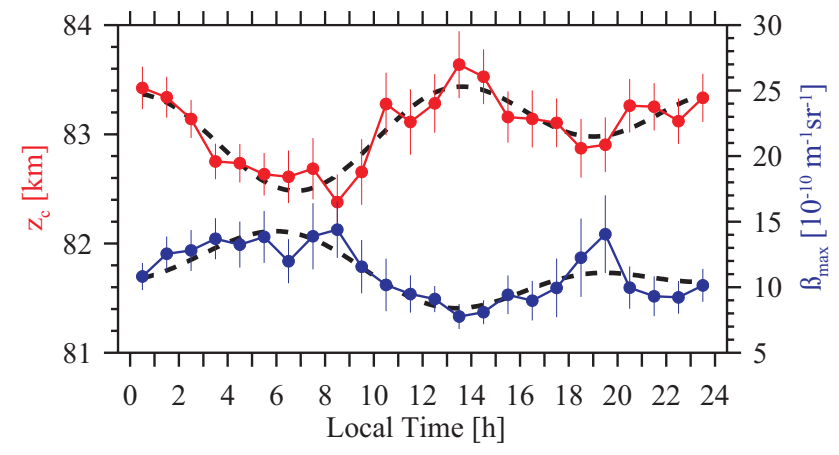

Fig. 3. Diurnal variation of NLC altitude (red circles) and brightness (blue circles) above ALOMAR for the integrated data set from 1997 to 2003. Only clouds brighter than $\beta_{\text {max }}>4 \times 10^{-10} \mathrm{~m}^{-1} \mathrm{sr}^{-1}$ are included. The vertical bars represent the $95 \%$ significance limits of the hourly mean values, and the dashed curves are harmonic fits to the data.

$\left(\left|A_{24} / A_{12}\right|=1.27\right)$ as a function of local time. The correlation coefficients for altitude and brightness fits are 0.91 and 0.85 , respectively, which indicates that the mean variation is well described by these periods. On average, over 7 years the variations of NLC altitude and brightness are in anti-phase, i.e. brighter clouds occur at lower altitudes than less bright clouds. 


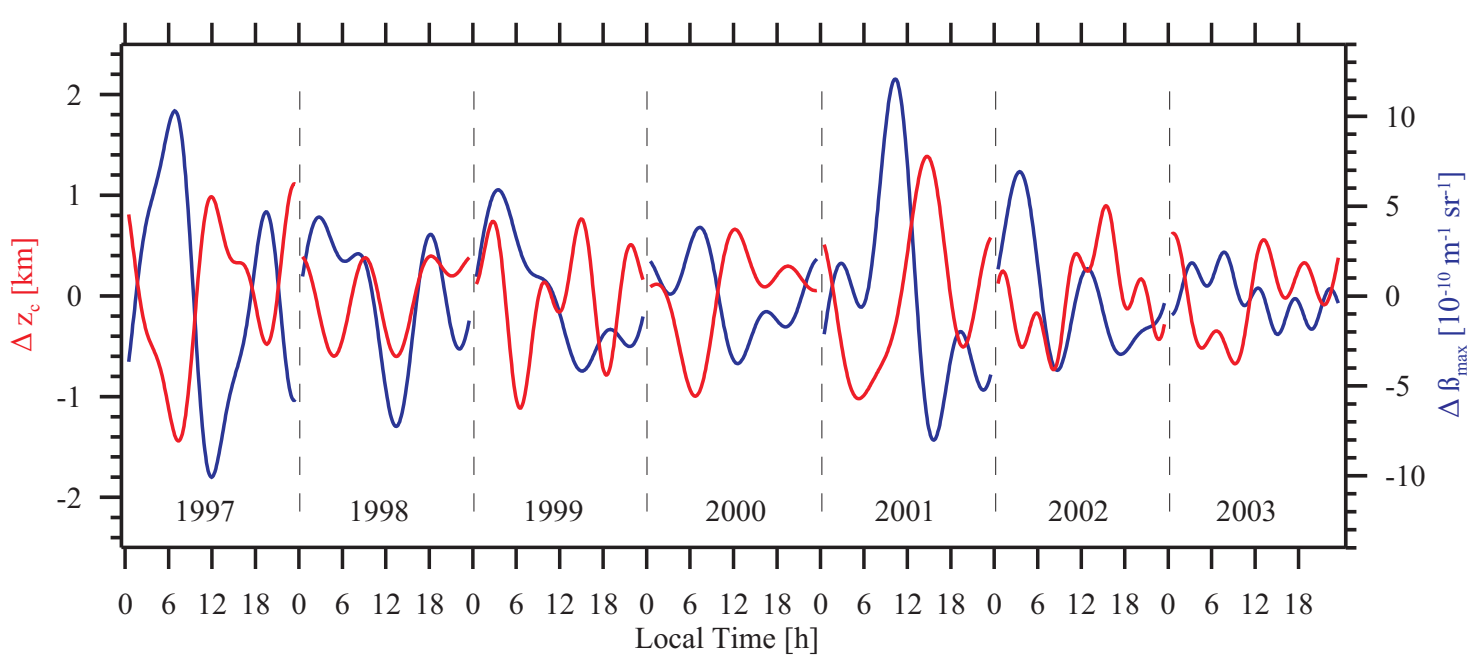

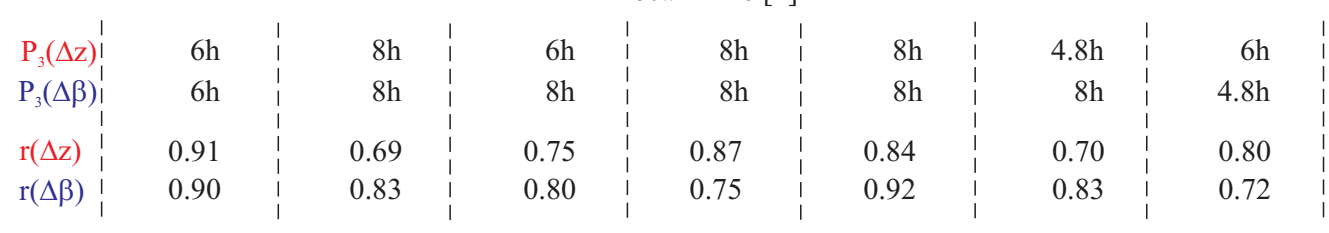

Fig. 4. Harmonic fits of the residual variations of NLC altitude (red) and brightness (blue) above ALOMAR for each individual year between 1997 and 2003. The fits to the hourly mean values are allowed for the 3 strongest oscillation periods. The third periods $P_{3}$ and the correlation coefficients $r$ of the fits are shown at the lower part.

To gain more insight into this persistent behavior, we investigate each individual year regarding the prevailing oscillation periods of the NLC parameters. All local times have good data coverage with a maximum of three missing hours per day in 2001. Figure 4 shows a composed time series of the residual variations of altitude and brightness. The harmonic analysis of the hourly mean values was done for each year separately and we allowed the fits for the 3 strongest oscillation periods which were determined using fast Fourier transformations. All years contain the 24- and 12-hour periods and show a variable third one. The latter reaches values of $4.8,6$, or $8 \mathrm{~h}$ and ensures a sufficient description of the data variability which is indicated by the correlation coefficients at Fig. 4. The strong anti-phase variations of altitude and brightness during 1997 which were attributed to a stable semidiurnal tide by von Zahn et al. (1998) are clearly visible. However, the following years reveal the more complex nature of the cloud parameters' variability:

1. Tendencies toward an in-phase behavior between altitude and brightness (e.g. 1998),

2. Different dominating periods between altitude and brightness (e.g. 1999, where the brightness is mainly controlled by a diurnal variation, unlike the altitude),

3. Both parameters are considerably influenced by shorter periods (e.g. 2003: $6 \mathrm{~h}$ and $4.8 \mathrm{~h}$ for altitude and brightness, respectively).

\section{Discussion}

As a consequence of the data reduction method used here, we determined local time dependencies of the NLC occurrence and properties which are not affected by a variable cloud detection efficiency caused, for example, by changes in solar elevation or atmospheric transmission.

The significant and persistent diurnal variation of the NLC occurrence frequency above ALOMAR, as determined from integration over 7 seasons (Fig. 2), is not observed at the South Pole, where during 2 seasons NLC occurred more or less constantly with $70 \%$ during the whole day, except a break between 13 and 14 UT (Chu et al., 2003). These differences could be explained by different supersaturation conditions at the NLC altitudes of both locations. Model calculations predict increasing supersaturation due to decreasing temperatures in the mesopause region towards higher latitudes (Berger and von Zahn, 2002), leading to more robust mean conditions for the formation of ice particles. As a result temperature fluctuations on time scales of several hours should have less impact on the dynamics of the NLC occurrence at higher compared to lower latitudes.

NLC data obtained by naked eye observations were interpreted differently regarding signatures of a diurnal variation of the cloud occurrence. The data set was acquired from locations at northwest Europe and is related to clouds well south of the pole region; the mean latitude of the southernmost edge of NLC is $60^{\circ}$. Unlike Schröder (2000), Gadsden (1998) determined a slight evening/morning asymmetry in the occurrence frequency of NLC, skewed to the morning 
hours. Taking into account the limited observation times due to restrictions by the illumination conditions of the visual observers, our maximum between 3 and 6 LT support the finding of Gadsden (1998).

Like the NLC occurrence, the 7 years integrated data of NLC altitude and brightness show a remarkable persistence of the diurnal variations. Table 1 shows the mean diurnal and semidiurnal components of NLC altitude and brightness above ALOMAR and the South Pole (Chu et al., 2003). Due to the periodicity of the harmonic fits we chose such combinations which yielded positive values for the amplitudes and minimum absolute values for the phases. Additionally, the brightness amplitudes at the South Pole were converted from $374 \mathrm{~nm}$ to our observation wavelength of $532 \mathrm{~nm}$ using Eq. (4) in Fiedler et al. (2003). Now we have calculated the phase differences between altitude and brightness for both locations and wave components. The absolute values of the phase shifts between the diurnal components of altitude and brightness for each location are comparable (8-10 h), but the shifts between the semidiurnal components are different. At ALOMAR it is nearly half of the period $(5.62 \mathrm{~h})$, whereas there is only a negligible shift $(0.57 \mathrm{~h})$ at the South Pole. This accounts for the ALOMAR-South Pole difference in the relationship between altitude and brightness, and shows the high sensitivity of the observed overall behavior to the phase difference of their semidiurnal waves.

Calculations with the COMMA/IAP model, a 3-D general circulation model of the middle atmosphere, including simplified ice particle microphysics, show that the diurnal and semidiurnal change in NLC altitude and brightness is due to the local time-dependent behavior of the synoptic vertical background wind which, in combination with the actual value of the sedimentation velocity, decreases the downward progression of the particles (Berger and von Zahn, 2002). The consistent set of atmospheric parameters used for modeling of the existence and transport of ice particles, indeed produces a phase shift between the (tidal caused) variations of altitude and brightness for the latitude of our measurements. The value of $\sim 3 \mathrm{~h}$, however, is fairly in the middle of the observed mean conditions above ALOMAR (anti-phase, 7 years mean) and the South Pole (in-phase, 2 years mean) (Chu et al., 2003).

The persistence in the variations of both the NLC occurrence and properties within our integrated 7-year data set argues strongly for tidal effects. Consequently, one should expect comparable diurnal variations of NLC parameters along the circle of latitude which, however, is not observed by the Rayleigh lidar at Sondrestrom, Greenland $\left(67^{\circ} \mathrm{N}, 51^{\circ} \mathrm{W}\right)$. At this location a strong influence and continuous presence of gravity waves seems to mask tidal influences on the observed NLC parameters (Thayer et al., 2003). According to model calculations involving the microphysics of the NLC particles, the authors found that, in particular short-period (2$3 \mathrm{~h}$ ) gravity-wave activity reproduced the behavior observed in the ensemble cloud properties. These waves, however, tend to destroy NLC (Rapp et al., 2002). Portnyagin et al. (2004) investigated the wind regime parameters at the Arc-
Table 1. Mean diurnal and semidiurnal components of NLC altitude $[\mathrm{km}]$ and brightness $\left[10^{-10} \mathrm{~m}^{-1} \mathrm{sr}^{-1}\right]$ above ALOMAR and the South Pole (Chu et al., 2003). The data sets contain 7 NLC seasons at ALOMAR and 2 seasons at the South Pole. Phases refer to minimum absolute values and are given in LT and UT hours for ALOMAR and the South Pole, respectively. The brightness amplitudes for the South Pole data are converted (see text).

\begin{tabular}{lllrrrr}
\hline & & $A_{0}$ & $A_{12}$ & $\phi_{12}$ & $A_{24}$ & $\phi_{24}$ \\
\hline ALOMAR & $\beta_{\max }$ & 11.1 & 1.5 & 6.50 & 1.9 & 4.15 \\
& $z_{c}$ & 83.1 & 0.32 & 0.88 & 0.25 & -5.68 \\
South Pole & $\beta_{\max }$ & 21.4 & 2.2 & -4.41 & 1.9 & -2.71 \\
& $z_{c}$ & 84.9 & 0.15 & -4.98 & 0.21 & 5.57 \\
\hline
\end{tabular}

tic mesosphere/lower thermosphere (MLT) region from measurements of a ground-based radar network. They find for the altitude region between 80 and $100 \mathrm{~km}$ a distinct 12 -h oscillation in the wind data and conclude from the zonal wave numbers that this behavior is mainly related to the semidiurnal tidal wave, which propagates westward following the apparent motion of the Sun.

Comparing the NLC occurrence frequency and brightness of our 7-year averaged data set between 18 and 20 LT we find an interesting relationship. The enhanced occurrence of strong NLC (magenta circles in Fig. 2b) during this time period is associated with a reduced occurrence of weak NLC (green circles in Fig. 2b), which is compensated in the overall occurrence (black filled circles in Fig. 2a). At the same time enhanced brightness values are observed (blue circles in Fig. 3). Presumably we see an increase in the particle sizes without simultaneously an additional supply of small particles. This would only redistribute the memberships in the brightness classes, leading to modified occurrences within each class, without a net change in the occurrence.

In Fig. 5 the diurnal and semidiurnal wave parameters ( $A_{24}, A_{12}, \phi_{24}, \phi_{12}$ ) of the NLC altitude and brightness fits, shown in Fig. 4, are displayed. The amplitude of the altitude varies between 200 and $800 \mathrm{~m}$ during phase variabilities of about $5 \mathrm{~h}$ for each wave component. Except for 1998, the phase of the semidiurnal component of the altitude remains remarkably stable within $2 \mathrm{~h}$ during 6 years, which is again an indication for the tidal driven particle properties above ALOMAR. In general, the phase shift of the semidiurnal components during each year varies between 3 and $6 \mathrm{~h}$ (see distance of filled circles in Fig. 5c), which tends to result in an anti-phase relation of altitude and brightness. Only in 2002, where Goldberg et al. (2004) found an unusual summer mesopause circulation and thermal structure, the phases are almost identical. The resultant in-phase behavior of both NLC parameters during this year is slightly hidden by the altitude period $P_{3}(\Delta z)$ of $4.8 \mathrm{~h}$, see Fig. 4 . During 1998 the phase shift of the semidiurnal waves turns out to be $3 \mathrm{~h}$. Additionally, the phase shift of the 8-h waves, present in altitude 

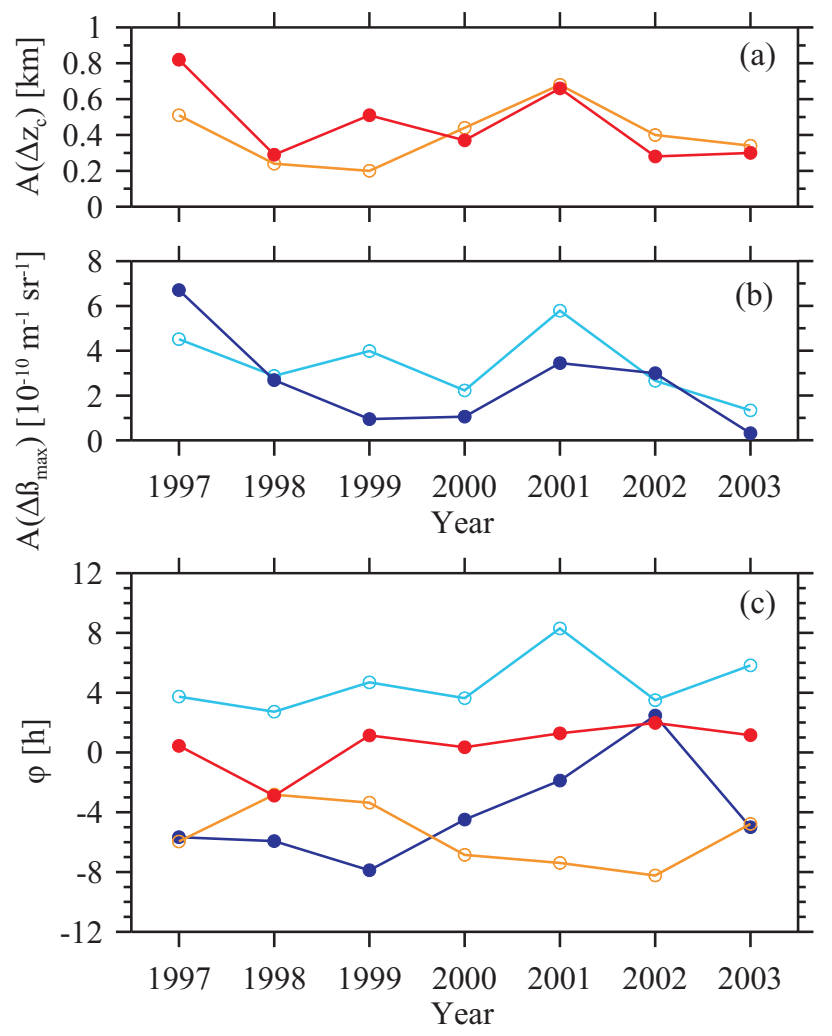

Fig. 5. Diurnal and semidiurnal wave parameters of NLC altitude and brightness above ALOMAR for each individual year: amplitudes (a) and (b), and phases (c) of the harmonic fits shown in Fig. 4.

Altitude: orange hollow circles (diurnal component), red filled circles (semidiurnal component). Brightness: cyan hollow circles (diurnal component), blue filled circles (semidiurnal component).

as well as brightness with a substantial amplitude, is only $0.7 \mathrm{~h}$, which leads to the observed mainly in-phase behavior.

\section{Conclusion}

Our lidar observations at an Arctic site yielded a multi-annual data set regarding noctilucent clouds, starting from 1997. Using these data, we find a distinct modulation of NLC occurrence, altitude, and brightness with respect to local time. All three parameters show the diurnal and semidiurnal components to be the most important periods contributing to the variability. The persistence of this behavior during the 7 years investigated here rules out gravity waves as a source for the variations, as their phases vary from day to day. Under additional consideration that westward propagating tides play a major role in the dynamics of the Arctic MLT region, as observed by ground-based radars, we conclude that NLC above ALOMAR are significantly controlled by atmospheric tides.

NLC occur preferably in the morning hours until 7 LT and show in general an anti-phase behavior between their altitude and brightness. The physical processes responsible for devi- ations from the anti-phase behavior between the NLC altitude and brightness and the corresponding variability are yet unknown. Obviously the altitude of the ice particles seems to be the more straightforward parameter of the clouds compared to the brightness, which is a result of complex growth processes and their time constants. We expect a better understanding of these relationships by extended model calculations based not only on climatological means but also on reanalysis data of tropospheric and stratospheric altitudes for taking into account, for example, large-scale internal gravity waves and planetary waves.

Acknowledgements. We would like to thank the staff at ALOMAR for their help in acquiring the extended data set with the ALOMAR RMR lidar as well as our colleagues G. Birkeli, R. Eixmann, K. H. Fricke, C. Fricke-Begemann, M. Gerding, T. Köpnick, S. Loßow, J. Schneider, A. Schöch, and U. von Zahn, who supported the measurements during nighttime and weekends. Part of this work was supported by the EU through the ALOMAR LSF/ARI program.

Topical Editor U.-P. Hoppe thanks G. Shepherd and another referee for their help in evaluating this paper.

\section{References}

Baumgarten, G., Fricke, K., and von Cossart, G.: Investigation of the shape of noctilucent cloud particles by polarization lidar technique, Geophys. Res. Lett., 29(8), 1-4, 2002a.

Baumgarten, G., Lübken, F.-J., and Fricke, K.: First observation of one noctilucent cloud by a lidar in two different directions, Ann. Geophys., 20, 1863-1868, 2002b,

SRef-ID: 1432-0576/ag/2002-20-1863.

Berger, U. and von Zahn, U.: Icy particles in the summer mesopause region: Three-dimensional modeling of their environment and two-dimensional modeling of their transport, J. Geophys. Res., 107(SIA 10), 1-32, 2002.

Carbary, J. F., Morrison, D., and Romick, G. J.: Maps of polar mesospheric clouds, J. Geophys. Res., 108(PMR 14), 1-8, 2003.

Chu, X. C., Gardner, C. S., and Roble, R. G.: Lidar studies of interannual, seasonal and diurnal variations of polar mesospheric clouds at the South Pole, J. Geophys. Res., 108(PMR 15), 1-20, 2003.

DeLand, M. T., Shettle, E. P., Thomas, G. E., and Olivero, J. J.: Solar backscattered ultraviolet (SBUV) observations of polar mesospheric clouds (PMCs) over two solar cycles, J. Geophys. Res., 108(PMR 12), 1-18, 2003.

Donahue, T. M., Guenther, B., and Blamont, J. E.: Noctilucent Clouds in Daytime: Circumpolar Particulate Layers Near the Summer Mesopause, J. Atmos. Sci., 29, 1205-1209, 1972.

Fiedler, J., Baumgarten, G., and von Cossart, G.: Noctilucent clouds above ALOMAR between 1997 and 2001: Occurrence and properties, J. Geophys. Res., 108(PMR 21), 1-9, 2003.

Fiedler, J., Baumgarten, G., von Cossart, G., and Schöch, A.: Lidar observations of temperatures, waves, and noctilucent clouds at $69^{\circ} \mathrm{N}$, in Remote Sensing of Clouds and the Atmosphere IX, edited by K. P. Schäfer, A. Comerón, M. R. Carleer, R. H. Picard, and N. I. Sifakis, Proceedings of SPIE, 5571 (SPIE, Bellingham, WA) 140-151, 2004.

Gadsden, M.: The North-West Europe data on noctilucent clouds: a survey, J. Atmos. Solar Terr. Phys., 60, 1163-1174, 1998. 
Goldberg, R. A., Pfaff, R. F., Holzworth, R. H., Schmidlin, F. J., Voss, H. D., Tuzzolino, A. J., Croskey, C. L., Mitchell, J. D., Friedrich, M., Murtagh, D., Witt, G., Gumbel, J., von Zahn, U., Singer, W., and Hoppe, U.-P.: DROPPS: A study of the polar summer mesosphere with rocket, radar and lidar, Geophys. Res. Lett., 28, 1407-1410, 2001.

Goldberg, R. A., Fritts, D. C., Williams, B. P., Lübken, F.-J., Rapp, M., Singer, W., Latteck, R., Hoffmann, P., Müllemann, A., Baumgarten, G., Schmidlin, F. J., She, C.-Y., and Krueger, D. A.: The MaCWAVE/MIDAS rocket and ground-based measurements of polar summer dynamics: Overview and mean state structure, Geophys. Res. Lett., 31, 1-5, 2004.

Hansen, G., Serwazi, M., and von Zahn, U.: First detection of a noctilucent cloud by lidar, Geophys. Res. Lett., 16, 1445-1448, 1989.

Hervig, M., Thompson, R. E., McHugh, M., Gordley, L. L., III, J. M. R., and Summers, M. E.: First confirmation that water ice is the primary component of polar mesospheric clouds, Geophys. Res. Lett., 28, 971-974, 2001.

Höffner, J., Fricke-Begemann, C., and Lübken, F.-J.: First observations of noctilucent clouds by lidar at Svalbard, $78^{\circ} \mathrm{N}$, Atmos. Chem. Phys., 3, 1101-1111, 2003.

SRef-ID: 1680-7324/acp/2003-3-1101.

Jesse, O.: Die Beobachtung der leuchtenden Wolken, Meteor. Z., Mai, 179-181, 1887.

Lübken, F.-J.: Thermal structure of the Arctic summer mesosphere, J. Geophys. Res., 104, 9135-9149, 1999.

Müller, K., Baumgarten, G., Siebert, J., and Fricke, K. H.: The New Lidar Facility at Esrange, Kiruna, in Proceedings $13^{\text {th }}$ ESA Symposium on European Rocket and Balloon Programmes and Related Research, edited by B. Kaldeich-Schürmann, Öland, Sweden, 129-134, 1997.

Portnyagin, Y. I., Solovjova, T. V., Makarov, N. A., Merzlyakov, E. G., Manson, A. H., Meek, C. E., Hocking, W., Mitchell, N., Pancheva, D., Hoffmann, P., Singer, W., Murayama, Y., Igarashi, K., Forbes, J. M., Palo, S., Hall, C., and Nozawa, S.: Monthly mean climatology of the prevailing winds and tides in the Arctic mesosphere/lower thermosphere, Ann. Geophys., 22, 33953410, 2004.

SRef-ID: 1432-0576/ag/2004-22-3395.
Rapp, M., Lübken, F.-J., Müllemann, A., Thomas, G. E., and Jensen, E. J.: Small-scale temperature variations in the vicinity of NLC: Experimental and model results, J. Geophys. Res., 107(AAC 11), 1-20, 2002.

Romejko, V. A., Dalin, P. A., and Pertsev, N. N.: Forty years of noctilucent cloud observations near Moscow: Database and simple statistics, J. Geophys. Res., 108(PMR 10), 1-7, 2003.

Schröder, W.: On the diurnal variation of noctilucent clouds, Quart. J. Hung. Met. Serv., 104, 53-59, 2000.

Shettle, E. P., Thomas, G. E., Olivero, J. J., Evans, W. F. J., Debrestian, D. J., and Chardon, L.: Three-satellite comparison of polar mesospheric clouds: Evidence for long-term change, J. Geophys. Res., 107(ACL 2), 1-9, 2002.

Thayer, J. P., Rapp, M., Gerrard, A. J., Gudmundsson, E., and Kane, T. J.: Gravity-wave influences on Artic mesospheric clouds as determined by a Rayleigh lidar at Sondrestrom, Greenland, J. Geophys. Res., 108(PMR 17), 1-12, 2003.

Thomas, G. E., McPeters, R. D., and Jensen, E. J.: Satellite observations of polar mesospheric clouds by the solar backscattered ultraviolet spectral radiometer: Evidence of a solar cycle dependence, J. Geophys. Res., 96, 927-939, 1991.

von Cossart, G., Fiedler, J., and von Zahn, U.: Size distributions of NLC particles as determined from 3-color observations of NLC by ground-based lidar, Geophys. Res. Lett., 26, 1513-1516, 1999.

von Zahn, U., von Cossart, G., and Fiedler, J.: Tidal variations of noctilucent clouds measured at $69^{\circ} \mathrm{N}$ latitude by groundbased lidar, Geophys. Res. Lett., 25, 1289-1292, 1998.

von Zahn, U., von Cossart, G., Fiedler, J., Fricke, K. H., Nelke, G., Baumgarten, G., Rees, D., Hauchecorne, A., and Adolfsen, K.: The ALOMAR Rayleigh/Mie/Raman lidar: Objectives, configuration, and performance, Ann. Geophys., 18, 815-833, 2000.

SRef-ID: 1432-0576/ag/2000-18-815. 